\title{
The Influence of Dysfunction of the Autonomic System and the Thyroid Gland on the Course of Bronchial Asthma (BA) in Children
}

\author{
Mavjuda Abdullaeva', Gulnorakhon Kasimova2, Esan Yaxudayev³, \\ Mavlyuda Sakhibova ${ }^{4}$, Zamira Bakhavadinova ${ }^{5}$
}

Scopus'

\begin{abstract}
'PhD, Docent, Head of Department of Propaedeutic of Childhood Diseases and the Outpatient Pediatrics, Andijan State Medical Institute, Andijan, Uzbekistan; 'PhD, Senior Lecturer, Department of Propaedeutic of Childhood Diseases and the Outpatient Pediatrics, Andijan State Medical Institute, Andijan, Uzbekistan; ${ }^{3}$ PhD, Docent, Department of Propaedeutic of Childhood Diseases and the Outpatient Pediatrics, Andijan State Medical Institute, Andijan, Uzbekistan; ${ }^{4}$ Assistant, Department of Propaedeutic of Childhood Diseases and the Outpatient Pediatrics, Andijan State Medical Institute, Andijan, Uzbekistan; ${ }^{5}$ Senior Lecturer, Department of Propaedeutic of Childhood Diseases and the Outpatient Pediatrics, Andijan State Medical Institute, Andijan, Uzbekistan.
\end{abstract}

\section{ABSTRACT}

Research on BA, not carried out a comparison of changes in indicators of thyroid function at different severity of the disease, has, in our opinion, extremely important to persons living in regions of endemic goiter, one of which is the Fergana Valley of Uzbekistan. On the other hand, thyroid hormones have a significant impact on the respiratory system. Thus, the influence of thyroid hormones on the formation of the respiratory system revealed already at the stage of fetal development. The inner piece of the embryo forms the respiratory organs and the main part of the thyroid. Its hormones affect the synthesis of receptors and the production of surfactant. Autonomic dysfunction is one of the urgent problems of modern medicine. The nature of the body's response to stress depends on the initial state of the regulatory mechanisms of VNS. An imbalance of the links of the VNS is one of the pathogenetic mechanisms of the occurrence of various somatic diseases or complications of infectious diseases. No diseases in which the ANS was not involved. Over the last decade, studies of autonomic dysregulate in norm and pathology, as a result of perceived need, has a significant place in clinical and experimental medicine.

Key Words: Autonomic dysfunction, Asthma, Thyroid gland, Vegetative status

\section{INTRODUCTION}

The autonomic nervous system is controlled by the Central nervous system and is the primary regulator of all physiological processes in the body. In 1981, A. M. Weiner has shown that autonomic dysfunction is disturbed neurotransmitter metabolism, there is a hyper - and hypocholesterolemic peripheral and Central receptors. It is possible not only the development of the various manifestations of dysfunction of the respiratory system (shortness of breath psychogenic nature, psychogenic cough, hyperventilation syndrome) but also the transition of vegetative dystonia in psychosomatic disease, particularly in asthma ${ }^{5-7}$.

Vegetative status, most adolescents with asthma of moderate severity in the period of exacerbation is characterized by the background sympathicotonia, autonomic reactivity of high normo - or hypersympathicotonic type under normal para- sympathetic tone of the option and a sufficient vegetative provision of activity. In adolescents with a severe course of BA takes place a pronounced imbalance of autonomic regulation, characterized by a decreased tone of the sympathetic division of the autonomic nervous system alone, option asympathicotonic reaction to orthostatic load with insufficient vegetative providing of activity of organs and systems. In adolescents with moderate asthma during the exacerbation period, electrical myocardial instability predominates amid sympathicotonia mainly in the form of impaired automatism; in patients with a severe course of the disease, various variants of rhythm and conduction disturbance are observed in combination with a change in the processes of myocardial repolarization ${ }^{9,13}$.

In any pathological process and in $\mathrm{AD}$, in particular, there is a violation of adaptive-compensatory processes, that is, disadaptation. These mechanisms are under the direct con-

\section{Corresponding Author:}

Dr. Mavjuda Abdullaeva, PhD, Docent, Head of Department of Propaedeutic of Childhood Diseases and the Outpatient Pediatrics, Andijan State Medical Institute, Andijan, Uzbekistan; Email: jovohir99@mail.ru

ISSN: $2231-2196$ (Print)

ISSN: 0975-5241 (Online)

Received: 19.04 .2020

Revised: 05.06 .2020

Accepted: 17.06 .2020

Published: 22.07 .2020 
trol of the vegetative structures of the body ${ }^{1,4,9}$. The ANS maintains the homeostatic balance of the body, regulates its functions, and ensures its adaptation to the most diverse pathological effects 5 . The ANS, as the leading center for regulating adaptation, determines the diversity of geno- and phenotypic (biosocial) factors of adaptation in the body. Three types of activity are manifested: normo-, sympathico-, parasympathico-tropic with predominance in the last two cases of antagonistic adreno- or cholinergic effects on body functions $^{8,14}$.

\section{MATERIALS AND METHODS}

To identify the autonomic dysfunction table was used as criteria reflecting the activity of the sympathetic and parasympathetic divisions of the ANS - 20 signs. Analyzed color of the skin, recorded the presence of vasomotor disorders according to the type of General or local pallor, cyanosis. Recorded the presence of trophic changes of skin and its appendages according to the type of dryness, hyperhidrosis, researched local dermographism. Studied signs of instability from the CCC. During the examination, pay attention to the signs of disorders of the gastrointestinal tract, allergic reactions. Took into account the temperament of sick children, mental and physical activity, sleep state. The study of the autonomic provision in ortoclinostatic the sample.

Orthostatic test - tests of functional diagnostics based on the measurement of various parameters of blood circulation, occurs under the influence of orthostatic loading.

To conduct O. p. used 2 types of physical activity - active (when the sick person goes) and passive (tilt-test on a rotating table, while skeletal muscle has less impact on the hemodynamic adaptation). There are options with the use of drugs (the study of functional reserves), bandaging of the lower extremities (identifying the role of varicose veins in the pathological blood pressure decrease when the sample of Challonge (see below).

Test with physical load (test of Salonga, she Proba Martin). Shoulder impose cuff for measuring blood pressure and take it off before the end of the sample. Offer the patient for 10-15 minutes to lie down quietly, and measure his blood pressure and pulse rate every 1-2 minutes When you get duplicate values, they are mistaken for the original. Offer the patient to calmly stand up, put your feet shoulder-width apart, and stand relaxed for $10 \mathrm{~min}$. Measurement of blood pressure and pulse rate, assessment of subjective feelings of the patient - immediately after getting up and then at the end of each minute. The appearance of dizziness, weakness, "flashing of lightning" the test is stopped. After 10 min the patient is asked to lie down again and measure blood pressure and pulse after $30 \mathrm{sec}, 1 \mathrm{~min} 12 \mathrm{sec}$, and $3 \mathrm{~min}$. (counts only $1+10+3=14$ measurements).
According to the measurement results build a graph where the abscissa shows the time, min, and y-axis - the value of the blood pressure and heart rate. Evaluate the results according to the degree and nature of the variance curves of blood pressure and pulse with changes in the health of the patient.

\section{RESULTS}

In children, thyroid hormones regulate all types of metabolism in the body, act on all cells, and stimulate tissue respiration. Therefore, the slightest dysfunction of thyroid hormones in the body causes serious, sometimes irreversible disorders ${ }^{12}$.

In children of the 1st group, the functions of the thyroid gland are preserved, while in the 2nd group, a decrease in functions is noted.

A mild degree was determined in 32 (66.7\%) children from group 1 and $4(7.4 \%)$ in 2 groups, an average degree in 10 (20.8\%) - 1 group and in 7 (13.0\%) -2 groups, and finally, a severe degree in $6(12.5 \%)-1$ group and in $43(79.6 \%)-2$ groups (Table 1).

Table 1: Distribution of children examined by the severity of asthma

\begin{tabular}{lccccc} 
Stages & \multicolumn{2}{c}{ Group 1 $(\mathbf{n = 4 8})$} & \multicolumn{2}{c}{$\begin{array}{c}\text { Group 2 } \\
(\mathbf{n = 5 4})\end{array}$} & P \\
& abs & $\%$ & abs & $\%$ & \\
& 32 & 66,7 & 4 & 7,4 & $<0,001$ \\
Mild & 10 & 20,8 & 7 & 13,0 & $>0,05$ \\
$\begin{array}{l}\text { Moderate } \\
\text { severity }\end{array}$ & & & & & \\
Severe severity & 6 & 12,5 & 43 & 79,6 & $<0,001$ \\
\hline
\end{tabular}

The data obtained completely fit into a state that proves a reduced thyroid function. The clinical manifestations of thyroid hypofunction are diverse, many of them are nonspecific, and certain difficulties in its timely recognition are associated with this (Table 2).

Table 2: The frequency of clinical manifestations of AD in patients with preserved (1 group) and reduced thyroid function (2 groups) (in $\%)$

\begin{tabular}{|c|c|c|}
\hline Manifestations & $\begin{array}{l}1 \text { group } \\
\left(\mathrm{n}=\mathbf{4}^{8}\right)\end{array}$ & $\begin{array}{l}2 \text { group } \\
(\mathbf{n}=54)\end{array}$ \\
\hline Breathing rate & $\begin{array}{l}\text { Normal breathing } \\
\text { rapid up to } 30 \% \text { of } \\
\text { the norm }\end{array}$ & $\begin{array}{l}\text { Severe expiratory } \\
\text { dyspnea, more than } \\
30-50 \% \text { of the norm }\end{array}$ \\
\hline
\end{tabular}

ment muscles in

the act of breathing

Whistlingintensity Wheezing, usu- Pronounced breathing ally at the end of exhalation wheezing on inhalation and exhalation or mosaic breathing 
Table 2: (Continued)

\begin{tabular}{|c|c|c|}
\hline Manifestations & $\begin{array}{l}1 \text { group } \\
(n=48)\end{array}$ & $\begin{array}{l}2 \text { group } \\
(\mathrm{n}=54)\end{array}$ \\
\hline Bloating & not pronounced & expressed \\
\hline Heart rate & Mildly expressed & $\begin{array}{l}\text { tachycardia, brady- } \\
\text { cardia }\end{array}$ \\
\hline Forced position & No & $\begin{array}{l}\text { Often, especially } \\
\text { at night and in the } \\
\text { morning }\end{array}$ \\
\hline $\begin{array}{l}\text { Sphere of con- } \\
\text { sciousness }\end{array}$ & $\begin{array}{l}\text { Not changed, } \\
\text { sometimes arousal }\end{array}$ & $\begin{array}{l}\text { Arousal, fear, often } \\
\text { "respiratory panic" }\end{array}$ \\
\hline $\begin{array}{l}\text { The degree of re- } \\
\text { striction of physical } \\
\text { activity }\end{array}$ & is absent & expressed \\
\hline
\end{tabular}

As the material, are given in table 3 reduced thyroid function was characterized by a decrease in the concentrations of $\mathrm{T}$, T4, and an increase in TSH levels, severe intra-Centralperipheral dissociation.

The level of triiodothyronine in group 1 decreased by $12.1 \%$ regarding the control group, in children of 2 groups by $41.1 \%$, and the level of thyroxine levels of thyroxine in children of the 1 st group decreased slightly, by only $4.4 \%$ and that in group 2 the level was decreased by $52.2 \%(\mathrm{P}<0.001)$.

The decrease in the level of thyroid hormones affects breathing through such mechanisms as reducing metabolic oxygen demand and the development of hypoventilation of the lungs, increased pressure in the left ventricle, remodeling of the respiratory muscles and lungs, an increase in hematocrit, the change in the level of neurotransmitters (serotonin, histamine) in brain areas involved in the control of breathing. As for thyroid-stimulating hormone, the reverse is true, the level increases in children of the 1 st group is $9.2 \%$, and in children of 2 groups of $67.6 \%$ (Table. 3 ).

Table 3: Indicators of thyroid function in patients with preserved and reduced thyroid function

\begin{tabular}{|c|c|c|c|}
\hline Indicators & $\mathrm{Kg}(\mathrm{n}=\mathbf{4 0})$ & $\begin{array}{c}\text { Group } 1 \\
(n=48)\end{array}$ & Group $2(n=54)$ \\
\hline $\begin{array}{l}\text { Triiodothy- } \\
\text { ronine }\left(\mathrm{T}_{3}\right) \\
\text { nmol / L }\end{array}$ & $1,41 \pm 0,07$ & $1,24 \pm 0,13$ & $0,83 \pm 0,09^{* * * \cdots}$ \\
\hline $\begin{array}{l}\text { Thyroxine } \\
\left(\mathrm{T}_{4}\right), \text { nmol } \\
\text { / L }\end{array}$ & $71,00 \pm 1,85$ & $67,90 \pm 2,29$ & $33,91 \pm 0,56^{* * * \cdots}$ \\
\hline $\begin{array}{l}\text { Thyroid- } \\
\text { stimulating } \\
\text { hormone } \\
\text { (TSH), } \\
\text { nmol/ L }\end{array}$ & $4,38 \pm 0,09$ & $4,74 \pm 0,21$ & $7,34 \pm 0,11^{* * * \cdots}$ \\
\hline $\mathrm{TTG} / \mathrm{T}_{3}$ & $2,38 \pm 0,054$ & $3,82 \pm 0,25$ & $8,84 \pm 0,54$ \\
\hline $\mathrm{TTG} / \mathrm{T}_{4}$ & $0,0420 \pm 0,0003$ & $0,069 \pm 0,002$ & $0,217 \pm 0,009$ \\
\hline
\end{tabular}

Note: The differences about the data of the control group are significant $\left({ }^{*} \mathrm{P}<0.05,{ }^{* *}-\mathrm{P}<0.01,{ }^{*} * * \mathrm{P}<0.001\right)$; - differences relative to data group 1 significant $(\bullet-\mathrm{P}<0,05, \bullet-\mathrm{P}<0.01, \bullet \bullet$ $-\mathrm{P}<0.001)$

\section{DISCUSSION}

Children with asthma are more prone to vascular dystonias of hypertonic than hypotonic type. Similar relations cases, increasing the frequency of hypertension in school-age children with underactive thyroid was discovered previously by other researchers in our region, although it is known that renin activity and aldosterone levels in patients with hypothyroidism reduced somewhat. In our opinion, due to dystonia of the renin-angiotensin-aldosterone system, there is a delay of sodium in the body, increasing the volume of the extracellular fluid, contributing to reduced renal filtration in the glomeruli and increased sodium reabsorption in the tubules.

Changes of the cardiovascular system in children with reduced function of thyroid of group 2 was characterized by the appearance of systolic murmur at the apex $(17,1 \%)$, at the point, Botkin-Erba $(12,0 \%)$, the weakening of the tones at the apex ( 8.7 percent), few rise to the aorta $(15.7 \%)$ and pulmonary artery $(11,4 \%)$, the expansion of percussion borders of the heart $(21,4 \%)$, apparently associated with tonogennoy dilatation of the myocardium (17.1 percent). ECG changes included an increase in the amplitude of P wave and QRS complex, migration of the pacemaker, the violation of intraventricular conductivity, and high frequency of violations of the processes repolarization.

Low thyroid function of the thyroid was accompanied by severe asthma. Asthma attacks arise 2-3 times a week and the bowl, with about equal frequency in day and night, lasting from 3 to 6 hours or more; all patients in this group noted the repeated recurrence of asthma attacks for one day. Patients during the attack took a forced position, they were fixed chest, felt a sense of fear ${ }^{17}$.

They had noisy wheezing with labored and extended exhalation, the active participation of auxiliary muscles in breathing, swelling of thorax, pallor of the skin, cyanosis of a nasolabial triangle, wings, nose, ears, fingertips, a cold sweat on the face and scalp. Percussion of the chest revealed box sound, the limitation of the lungs, and the omission of their lower bounds, narrowing the boundaries of the relative dullness of the heart.

Patients were heard from both sides a large number of different height dry rales and moist medium bubbling rale, there was an increase in blood pressure, tachycardia, muffled heart tones, functional systolic murmur at the apex of the heart, the focus of the second tone on pulmonary artery were detected signs of hypoxemia and hypercapnia. 
Bronchial asthma in children in the region of the Fergana valley, in most cases, occurs on the background of the decreased TG activity, and specific clinical symptoms of thyroid hypothyroidism are masked by symptoms of the underlying disease. The decrease in the functional activity of the thyroid apparatus is accompanied by severe, frequent development of asthma status, by involvement in the inflammatory process of the circulatory system refractory to antiinflammatory therapy. Peculiarities of the clinical course of BA patients with unchanged and decreased function of the thyroid have given the opportunity us to assume that the deterioration of the current and forecast role belongs to the dysfunction of this body. Changes in the functional state of the thyroid reflect in turn the implementation of the body's defense mechanisms in conditions of immune inflammation in this disease and lead to the creation of another "vicious circle" that is one of the mechanisms of self-maintenance of the pathological process. The imbalance of the functional state of the thyroid gland plays a major role in the deterioration and severity of bronchial asthma in children.

Subclinical (or "laboratory") hypothyroidism develops, as a rule, in patients with BA, moderate and severe. High frequency of detection of autoantibodies to thyroid peroxidase and thyroglobulin indicate the involvement of the inflammatory process in the thyroid gland, the nature of hormonal disorders in patients with asthma require further investigation and dynamic monitoring.

\section{CONCLUSION}

The vegetative status of the majority of children from 7 to 14 years with asthma of moderate severity in the period of exacerbation is characterized by the background sympathicotonia, autonomic reactivity of high normo - or hypersympathicotonic type under normal parasympathetic tone of the option and a sufficient vegetative provision of activity. In children with a severe course of BA takes place a pronounced imbalance of autonomic regulation, characterized by a decreased tone of the sympathetic division of the autonomic nervous system alone, option asympathicotonic reaction to orthostatic load with insufficient vegetative providing of activity of organs and systems.

Acknowledgment: Authors acknowledge the immense help received from the scholars whose articles are cited and included in references of this manuscript. The authors are also grateful to authors / editors / publishers of all those articles, journals and books from where the literature for this article has been reviewed and discussed.

\section{Conflict of interest: None}

Financial support: None

\section{REFERENCES}

1. Duran-Tauleria, E. Geographical and socioeconomic variation in the prevalence a symptoms in English and Scottish children / E. Duran-Tauleria, R. J. Rona. // Thorax. - 2009. - V. 54. - pp. 476-481.

2. Early exposure to house-dust mite and cat allergens and development of childhood asthma: a cohort study. Multicentre Allergy Study Group / S. Lau [et al.]. // Lancet. 2000. - V. 356. - pp. $1392-1397$.

3. Effect of asthma in childhood on psycho-social problems in the family / D. Gustafsson [et al.]. // J. Psychosom. Res. 2002. - V. 53(6). - pp. 1071 - 1075.

4. Eosinophil and neutrophil activity in asthma in a one-year trial with inhaler budesonide. The impact of smoking / B. Pedersen [et al.]. // Am. J. Respir. Crit. Care Med.- 1996,-V. 153.-pp. 1519 -1529 .

5. Erb, K. L. The role of Th2 type CD4+T cells and TA2 type CD8+cells in asthma / K. L. Erb, G. Le Gros. // Immunol. Cell. Biol. - 2005. - V. 74(2). - pp. 206-208.

6. Esamai, F. Prevalence of asthma, allergic rhinitis and dermatitis in primary school children in Uasin Gishu district, Kenya / F. Esamai, S. Ayaya, W. Nyandiko // East Afr. Med. J. - 2012. - V. 79(10). - pp. 514-518.

7. Evaluation of the association between St. John's Wort and elevated thyroid-stimulating hormone / B. Sc. Nicole Ferlco et al. / Pharmacotherapy. -2001. V. 21(12).-pp. 1574-1578.

8. Family history as a predictor of asthma risk / W. Burke [et al.]. // Am. J.Prev. Med. - 2003. - V.24(2). - pp. 160-169.

9. Family patterns of asthma, atopy and airway hyperresponsiveness: an epidemiological study // Clin. Exp. Allergy. 2000. -V. 30.-pp. 393-399.

10. Ferrar F. P. Prevalence of asthma and weezing in schoolchildren. The ISAAC in Curitiba-Brasil // Allergy. - 2007. - V. 52, suppl. 37. -P. 382-386.

11. Ferrence R., Ashley M. J. Protenting children from passive smoking // BMJ. - 2010. - V. 321. - pp. 310-311.

12. Mamarasulova D.Z. Personalized medicine: new or well-forgotten old?/European science review-2017-№3-4. DOI: http:// dx.doi.org/10.20534/ESR-17-3.4-52-54

13. Gergen P. J. Weiss K. B. Epidemiologist of asthma. Air pollution and asthma. // J. Allergy Clin. Immunol. - 2009. - V.104. - pp. 717-722.

14. Harris G. S. Shearer A. G. Beliefs that support the behavior of people with astma: a qualitative invtstigation // J Astma. - 2007. - Vol. 38, №5. - pp. 427-434.

15. Holgate S. T., Beasley R., Twentyman O. P. The pathogenesis and significance of bronchial hyperresponsiveness in airways disease // Clin. Sei. - 2007. - Vol. 73. - pp. 561-572.

16. Iniestra F. Gastroesophageal reflux disease in pediatric patients with asthma // Rev. Alerg. Mex. 2002. - V. 49(5). - pp. 152-156.

17. Ranjit S. Ambad, Rakesh Kumar Jha, Nandkishor Bankar, Brij Raj Singh, Ajinkya S. Ghogare, Ragini Patil. Role of prolactin and thyroid hormone in psychiatric disorders. International Journal of Psychosocial Rehabilitation, Vol. 24, Issue 06, 2020 page no 6001-6005. 